\title{
Comparison of in vitro chondrogenic potential of human mesenchymal stem cells derived from bone marrow and adipose tissue
}

\author{
L'uboš Danišovič ${ }^{1}$, Ivan Varga ${ }^{2,3}$, Štefan Polák ${ }^{2}$, Marcela Uličná ${ }^{1}$, Lívia Hlavačková ${ }^{4}$ \\ Daniel Böhmer ${ }^{1}$ and Ján Vojtaššák ${ }^{1}$ \\ ${ }^{1}$ Institute of Medical Biology and Genetics, Faculty of Medicine, Comenius University in Bratislava, Sasinkova 4, 81108 \\ Bratislava, Slovakia \\ ${ }^{2}$ Institute of Histology and Embryology, Faculty of Medicine, Comenius University in Bratislava, Sasinkova 4, 81108 \\ Bratislava, Slovakia \\ ${ }^{3}$ Institute of Histology and Embryology, Faculty of Medical Speciality Studies, Slovak Medical University, Limbová 12, \\ 83303 Bratislava, Slovakia \\ ${ }^{4}$ Institute of Pathology, Faculty of Medicine, Comenius University in Bratislava, Sasinkova 4, 81108 Bratislava, Slovakia
}

\begin{abstract}
In the present work, the human bone marrow and adipose tissue-derived mesenchymal stem cells (MSCs) were isolated and expanded under in vitro condition. After their phenotypic analysis, the chondrogenic differentiation was induced by using of the three-dimensional culture system without supplementation of growth factors, and their chondrogenic potential was compared. Obtained results proved that both types of MSCs undergo the process of chondrogenic differentiation. Comparative analysis showed that chondrogenic potential of adipose tissue-derived MSCs was slightly decreased in comparison with bone marrow-derived MSCs. However, both evaluated MSCs may play important role in the cartilage tissue engineering.
\end{abstract}

Key words: Chondrogenic potential - Mesenchymal stem cells - Bone marrow - Adipose tissue - In vitro study

\section{Introduction}

Inborn anomalies, pathological processes and injuries may lead in the degeneration of hyaline cartilage. It is difficult to treat these patients, because mature hyaline cartilage has a very limited self-healing potential (Strehl et al. 2005), and mitotic activity of chondrocytes is very low (Tew et al. 2000). Small defects are regenerated by the migration of chondrocytes (Hunziker and Rosenberg 1996). Full-thickness damages are healed by the formation of inferior fibrocartilage, but in many cases osteoarthritis develops and surgical intervention is the only option (Tuli et al. 2003).

Brittberg et al. (1994) has presented first important attempt for repair of hyaline cartilage defects by utilization of autologous chondrocytes. Unfortunately, this technique has

Correspondence to: Luboš Danišovič, Institute of Medical Biology and Genetics, Faculty of Medicine, Comenius University in Bratislava, Sasinkova 4, 81108 Bratislava, Slovakia

E-mail: lubos.danisovic@fmed.uniba.sk some disadvantages, such as the reacquisition of phenotype of chondrocytes expanded in vitro (Schnabel et al. 2002) and non-uniform distribution of cells (Sohn et al. 2002).

Several studies focused on the utilisation of adult mesenchymal stem cells (MSCs) isolated from bone marrow as an alternative to chondrocytes were performed (Lee et al. 2004a; Bosnakovski et al. 2005). MSCs are characterized by its selfrenewal ability. Moreover, they are capable of differentiating into different cell lineages, including chondrocytes under proper in vitro conditions (Pittenger et al. 1999). The in vitro differentiation of MSCs requires specific cell-cell interactions and additions of growth factors such as transforming growth factor- $\beta$ (TGF- $\beta$ ), bone morphogenetic proteins (BMPs) and insulin growth factor-1 (IGF-1) (Schmitt et al. 2003; Indrawattana et al. 2004). Bosnakovski et al. (2004) reported spontaneous chondrogenic differentiation of MSCs in three-dimensional culture system, without growth factors. However, the use of bone marrow-derived MSCs has some limitations like a discomfort and pain associated with bone marrow sampling, low cell quantity after isolation 
and decreased differentiation potential in older individuals (Banfi et al. 2002).

More recently, it has been reported that adipose tissue-derived MSCs obtained from liposuction can differentiate into various types of cells (Zuk et al. 2001; Gimble and Guilak 2003; Huang et al. 2004). The potential of utilization of these cells is attractive for the cartilage tissue engineering because subcutaneous fat is abundant in human body and liposuction procedure is minimally invasive for patient. Furthermore, yield of adiposederived tissue MSCs and their proliferation rates is higher in comparison to bone marrow (Strem and Hedrick 2005).

In the present study, we isolated human bone marrow and adipose tissue-derived MSCs and compared their chondrogenic potential under in vitro conditions.

\section{Materials and Methods}

\section{Sampling procedure}

Bone marrow, adipose tissue and hyaline cartilage were collected from male donors ( $n=2 ; 27$ and 33-year-old) during planed orthopaedic surgeries, following patient's informed consent. All samplings were performed in accordance with The Helsinki Declaration and were approved by the local ethical committee.

\section{Isolation and cell culture of MSCs}

Bone marrow-derived MSCs were isolated from fresh samples, which were supplemented with $20 \mathrm{U} \cdot \mathrm{ml}^{-1}$ heparin in sterile physiologic solution as described previously (Pittenger at al. 1999; Bosnakovski et al. 2004). Nucleated cells were separated by the gradient centrifugation using FicollPaque (Amersham Biosciences, Sweden) at $1800 \mathrm{rpm}$ for $40 \mathrm{~min}$. Obtained cells were washed twice in phosphate buffered solution (PBS; Oxoid, GB) and were centrifuged at $1200 \mathrm{rpm}$ for $5 \mathrm{~min}$. Pellets were resuspended in complete culture medium consisted of a-MEM (PAA, Austria), 20\% foetal bovine serum (FBS; PAA, Austria) and gentamicin in the final concentration of $160 \mu \mathrm{g} \cdot \mathrm{ml}^{-1}$ (Lek, Slovenia). The obtained cells $\left(2.5 \times 10^{5}\right.$ cells $\left./ \mathrm{ml}\right)$ were plated in $100 \mathrm{~mm}$ Petri dishes (TPP, Switzerland) and were cultured at $37^{\circ} \mathrm{C}$ in a humidified atmosphere containing $5 \% \mathrm{CO}_{2}$ in the air. After $24 \mathrm{~h}$, non-adherent cells were removed by changing the culture medium. During the following cultivation the medium was refreshed every three days. After 7-10 days, cells were detached by $0.25 \%$ trypsin (PAA, Austra) and sub-cultured up to third passage.

Adipose tissue-derived MSCs were obtained from fresh subcutaneous fat as described before (Gimble and Guilak 2003). Briefly, lipospirates were carefully rinsed with PBS and mechanically disaggregated by scalpel. Subsequently, adipose specimens were digested by $0.1 \%$ collagenase (Serva, Germany) in PBS for $60 \mathrm{~min}$ at $37^{\circ} \mathrm{C}$ with agitation at $50 \mathrm{rpm}$. Released cells and residual adipose tissues were centrifuged at $1200 \mathrm{rpm}$ for $5 \mathrm{~min}$. The supernatant layer of oil, fat and primary adipocytes, and the underlying layer of collagenase were aspirated. The pellet was resuspended in PBS with following centrifugation at 1200 $\mathrm{rpm}$ for $10 \mathrm{~min}$. The final pellet was resuspended in complete culture medium consisted of DMEM/F12 1: 1 (PAA, Austria) with $10 \%$ FBS and gentamicin in the final concentration of $160 \mu \mathrm{g} \cdot \mathrm{ml}^{-1}$. Cells were seeded at density of $2.5 \times 10^{5}$ cells $/ \mathrm{ml}$ in $100 \mathrm{~mm}$ Petri dishes and were incubated in a humidified atmosphere of $5 \% \mathrm{CO}_{2}$ in the air at $37^{\circ} \mathrm{C}$. Non-adherent cells were aspirated with medium after $24 \mathrm{~h}$ of cultivation and fresh medium was added. Culture medium was changed every three days. To obtain sufficient number of adipose-derived MSCs they were sub-cultured three times.

Chondrocytes were obtained from articular cartilage according protocols published previously (Brittberg et al. 1994). Briefly, cartilages were washed with PBS and mechanically disaggregated using scalpel. Obtained specimens were digested with $0.25 \%$ trypsin for $1 \mathrm{~h}$, followed by digestion with $0.1 \%$ collagenase for $12 \mathrm{~h}$ at $37^{\circ} \mathrm{C}$. DMEM/F12 $1: 1$ with $10 \%$ FBS was added to released cells and they were centrifuged at $1200 \mathrm{rpm}$ for $10 \mathrm{~min}$. The pellet was resuspended in DMEM/F12 1: 1 with 10\% FBS and gentamicin in the final concentration of $160 \mu \mathrm{g} \cdot \mathrm{ml}^{-1}$. Cells were seeded at density of $2.5 \times 10^{5}$ cells $/ \mathrm{ml}$ in $100 \mathrm{~mm}$ Petri dishes and were incubated in a humidified atmosphere of $5 \% \mathrm{CO}_{2}$ in the air at $37^{\circ} \mathrm{C}$. Chondrocytes were sub-cultured two times and culture medium was refreshed in three-day interval.

\section{Phenotypic analysis of MSCs}

Bone marrow-derived MSCs and adipose tissue-derived MSCs from the third passage were analyzed by direct and indirect immunofluorescence, according to protocols specific for each antibody. In each case 10,000 events were acquired and analyzed by a Coulter Epics ALTRA flow cytometer. The following antibodies (Table 1) were used for cell staining: antiCD29-PE, anti-CD44-FITC, anti-CD90-FITC, anti-CD105FITC (BD Pharmingen, USA); anti-CD31-FITC (Chemicon, USA); anti-CD45-PE-Cy5 (DakoCytomation, Denmark); anti-CD34-FITC, anti-HLA class I-FITC, anti-HLA class IIFITC (Exbio, Czech Republic); anti-human fibroblast surface protein (Sigma Aldrich, USA) with a secondary FITC-conjugated donkey anti-mouse IgG antibody (Chemicon, USA).

\section{Chondrogenic differentiation of MSCs}

For chondrogenic differentiation, a three-dimensional pellet culture system was used. Pellets were formed by centrifugation of $1 \times 10^{6}$ bone marrow-derived MSCs and adipose tissue-derived MSCs (both from third passage) at $1500 \mathrm{rpm}$ 
Table 1. Description of analysed markers

\begin{tabular}{|l|l|}
\hline Marker & Description \\
\hline CD29 & fibronectin receptor; general marker of MSCs \\
\hline CD31 & $\begin{array}{l}\text { platelet endothelial cell adhesion molecule; typical for endothelial cells, } \\
\text { lymphocytes, platelets, macrophages and fibroblasts }\end{array}$ \\
\hline CD34 & cell surface glycoprotein, typical for haematopoietic progenitor stem cells \\
\hline CD44 & receptor for hyaluronic acid; typical for specific types of MSCs \\
\hline CD45 & leukocyte common antigen; expressed in haematopoietic stem cells \\
\hline D90 & thymocyte differentiation antigen 1; general marker of stem cells \\
\hline CD105 & regulatory component of the TGF- $\beta$ receptor-cell complex; general marker of human MSCs \\
\hline HLA class I & component of human leukocyte antigen system; expressed by undifferentiated cells, including MSCs \\
\hline HLA class II & component of human leukocyte antigen system; predominantly expressed on haematopoietic cells but not in MSCs \\
\hline $\begin{array}{l}\text { Human fibroblast } \\
\text { surface protein }\end{array}$ & expressed by fibroblasts and macrophages \\
\hline
\end{tabular}

for $10 \mathrm{~min}$ in $15 \mathrm{ml}$ polypropylene tubes (TPP, Switzerland). The chondrogenic medium consisted of DMEM/F12 $1: 1$, $10 \%$ FBS and gentamicin in the final concentration of 80 $\mu \mathrm{g} \cdot \mathrm{ml}^{-1}$. Chondrocytes from the second passage cultured as pellets were used as a control. All tubes were maintained in the incubator at $37^{\circ} \mathrm{C}$ with humidified atmosphere of $5 \%$ $\mathrm{CO}_{2}$. The culture medium was carefully refreshed every third day during 21 days.

\section{Histological and immunohistochemical analysis}

After 21 days, the pellets were fixed in $4 \%$ paraformaldehyde for $4 \mathrm{~h}$, then dehydrated in ethanol and embedded in paraffin. Sections with a thickness of $5 \mu \mathrm{m}$ were cut from paraffin blocks, deparaffinized with xylene and rehydrated with distilled water. The obtained sections were stained with hematoxylin and eosin (Sigma Aldrich, USA) to visualize the morphology of the cells, with Masson's trichrome (Sigma Aldrich, USA) to visualize the collagenous matrix, and with alcian blue (Sigma Aldrich, USA) to visualize the acid mucopolysaccharides.

The presence of collagen type II was detected by immunohistochemistry. A monoclonal antibody directed against collagen type II (Chemicon, USA) was used in accordance with the manufacturer's recommendations.

\section{Results}

Bone marrow-derived MSCs and adipose tissue-derived MSCs grew as isolated colonies when primary plated. After 7-10 days they were sub-cultured and grew in confluent monolayer. Both types of cultured cells had a bipolar to polygonal fibroblast-like shape (Fig. 1). During further sub-cultivation (up to third passage) they maintained this
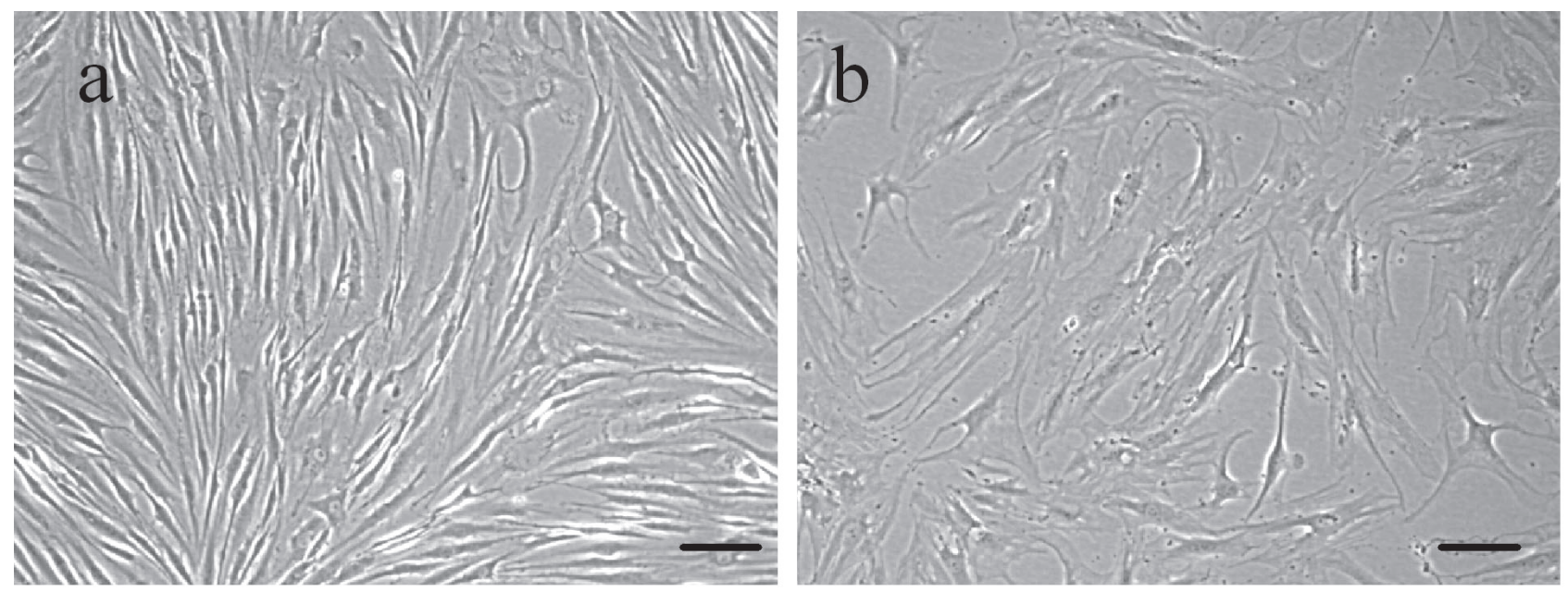

Figure 1. Human bone marrow-derived MSCs (a) and adipose tissue-derived MSCs (b), third passage of in vitro culture. Scalebar $=100 \mu \mathrm{m}$. 

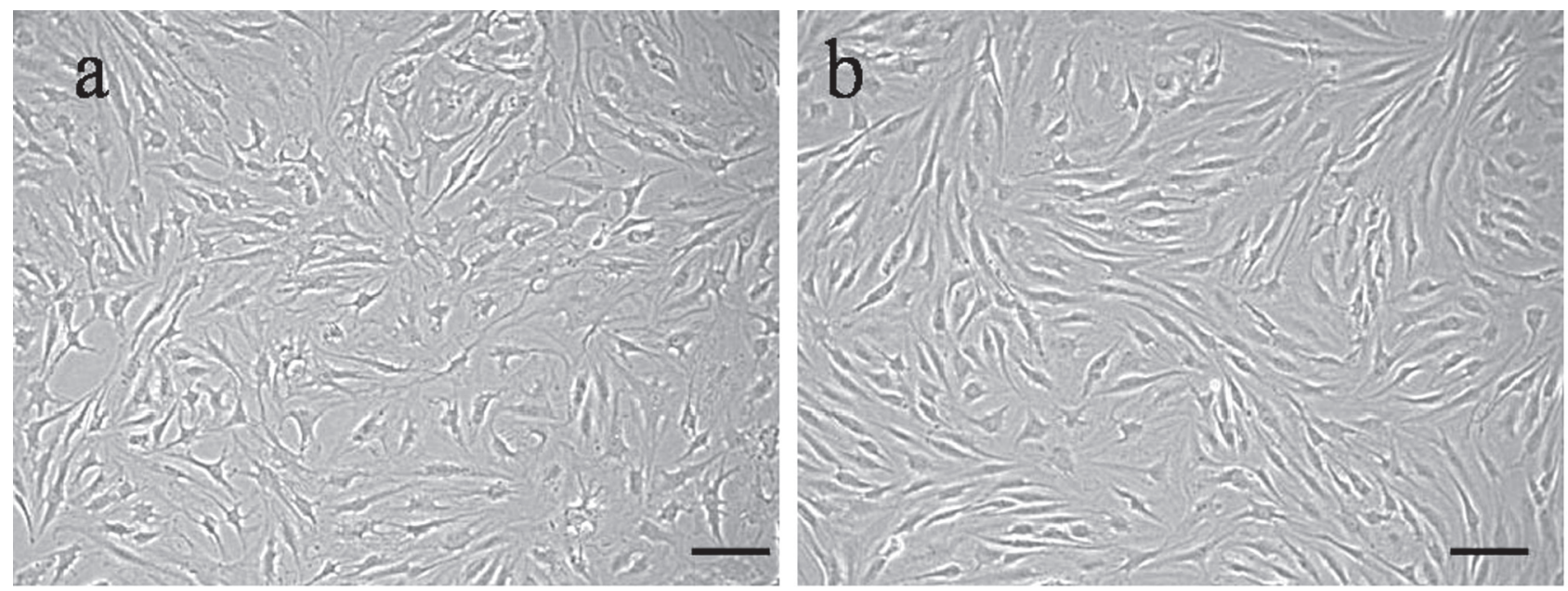

Figure 2. In vitro culture of human articular chondrocytes - primary culture (a) and third passage (b). Scalebar $=100 \mu \mathrm{m}$.

morphology. Moreover, any changes in their proliferation activity were not observed. Primary isolated chondrocytes had typical polygonal appearance. During following passages they gradually lost their original shape and showed fibroblast-like morphology (Fig. 2).

The results obtained from cytometric analysis (Table 2) showed that bone marrow-derived MSCs and adipose tissue-derived MSCs from third passage were positive for MSCs surface markers: CD29, CD44, CD90 and CD105. They were also HLA class I positive and HLA class II negative. The expression of haematopoietic and endothelial lineage markers CD31, CD34 and CD45 was not detected. Moreover, analysed cells did not express anti-human fibroblast surface protein.

When bone marrow-derived MSCs and adipose tissuederived MSCs were centrifuged into micromasses, condensation of the pellets into single aggregates was observed after

Table 2. Phenotypic analysis of bone marrow-derived and adipose tissue-derived MSCs

\begin{tabular}{|l|c|c|}
\hline Marker & $\begin{array}{c}\text { Bone marrow- } \\
\text {-derived MSCs }\end{array}$ & $\begin{array}{c}\text { Adipose tissue- } \\
\text {-derived MSCs }\end{array}$ \\
\hline CD29 & + & + \\
\hline CD31 & - & - \\
\hline CD34 & - & - \\
\hline CD44 & + & + \\
\hline CD45 & - & - \\
\hline CD90 & ++ & ++ \\
\hline HLA class I & ++ & ++ \\
\hline HLA class II & ++ & ++ \\
\hline Human fibroblast & - & - \\
\hline surface protein & - & - \\
\hline
\end{tabular}

- negative; + positive $(\leq 50 \%)$; ++ positive $(\geq 80 \%)$.
$24 \mathrm{~h}$. Any significant differences were not observed when compared with pellets formed by chondrocytes maintained in same culture system. The condensed pellets grew continually during further 21 days. They gradually became white and opaque. After termination of experiment, differences in size of agregates were not observed.

Photomicrographs of hematoxilin and eosin stained samples (Fig. 3) showed a homogenous cell distribution in all samples. Cells were mostly round with darkly stained nuclei what indicate their excessive proliferation. Pellets of bone marrow-derived MSCs and chondrocytes contained more actively synthesizing cells than did pellets of adipose tissue-derived MSCs. Moreover, the density of cells in adipose tissue-derived MSCs aggregates was lower when compared with bone marrow-derived MSCs and chondrocytes. Masson's trichrome staining showed that cells in each group were separated by extensive regions of diffuse extracellular matrix, which was predominantly collagenous (Fig. 4). Alcian blue staining visualized deposits of acid mucopolysaccharides (Fig. 5). The highest intensity of this staining was recorded in samples of chondrocytes, while the intensity in adipose tissue-derived MSCs samples was lowest.

Immunohistochemical labelling against collagen type II proved the presence of this chondrogenic marker in all samples after 21 days of cultivation (Fig. 6). Stronger staining was recorded in the pellets of chondrocytes and bone marrow-derived MSCs when compared with those of adipose tissue-derived MSCs.

\section{Discussion}

Recently, adult MSCs seem to be promising tool for cartilage tissue engineering (Salgado et al. 2006; Jorgensen 


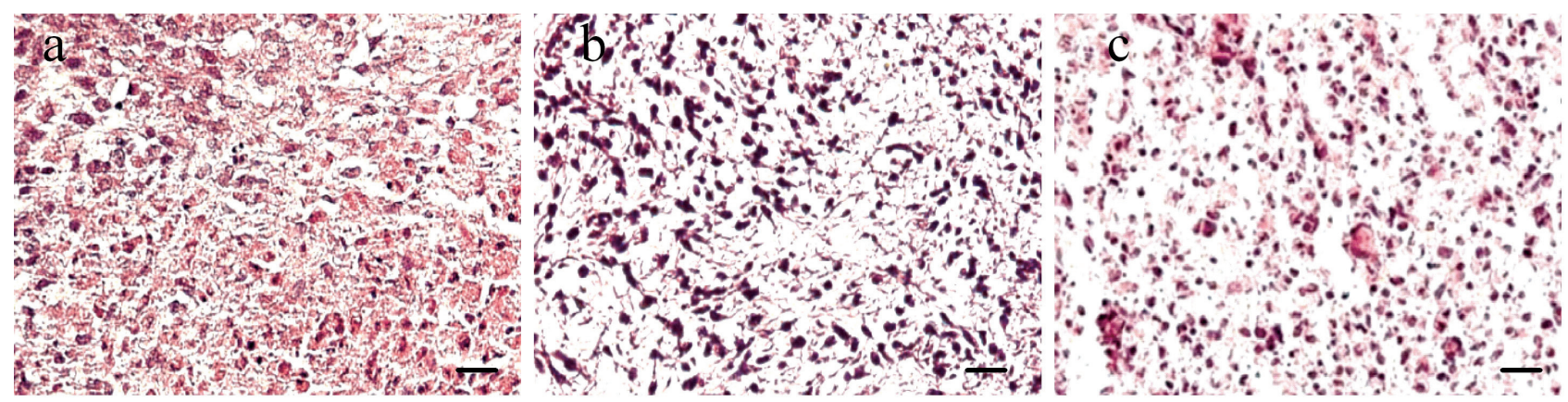

Figure 3. Hematoxylin and eosin staining of human bone marrov-derived MSCs (a), adipose tissue-derived MSCs (b) and chondrocytes (c).

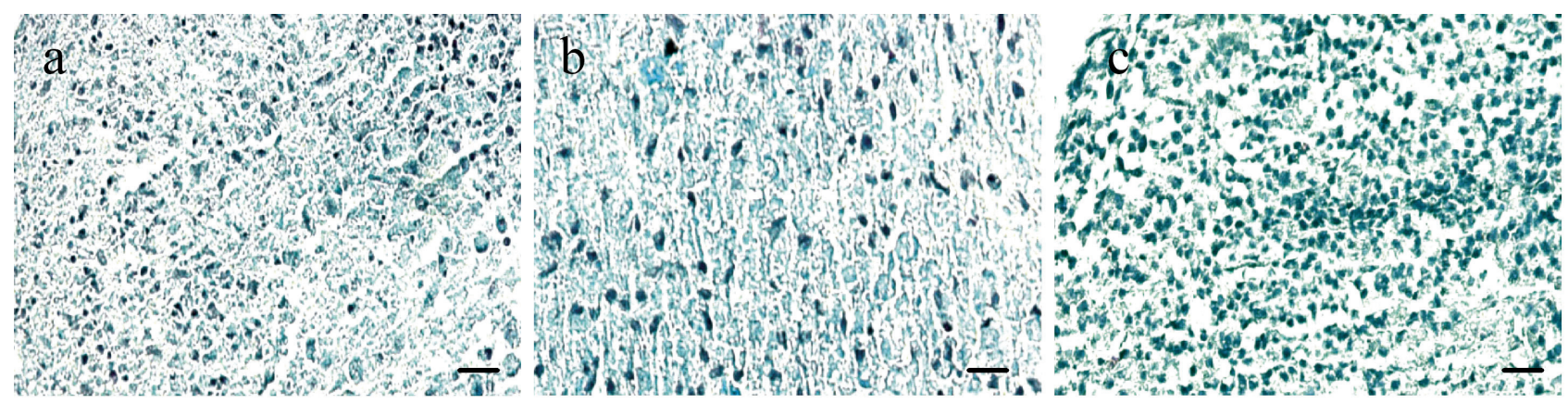

Figure 4. Masson's trichrome staining of human bone marrov-derived MSCs (a), adipose tissue-derived MSCs (b) and chondrocytes (c).
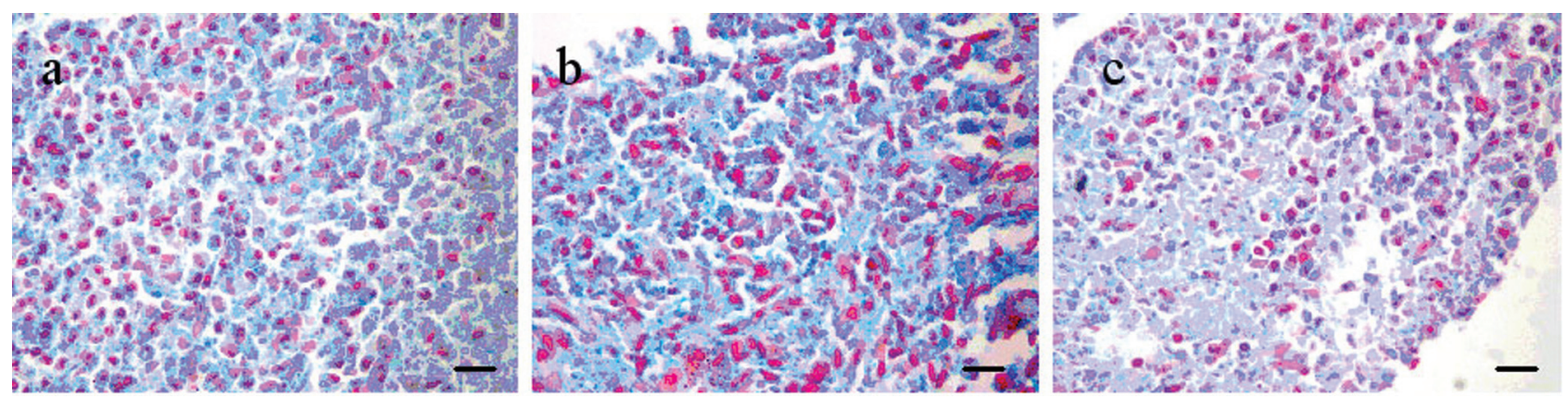

Figure 5. Alcian blue staining of human bone marrov-derived MSCs (a), adipose tissue-derived MSCs (b) and chondrocytes (c). The nuclei are stained by nuclear red.
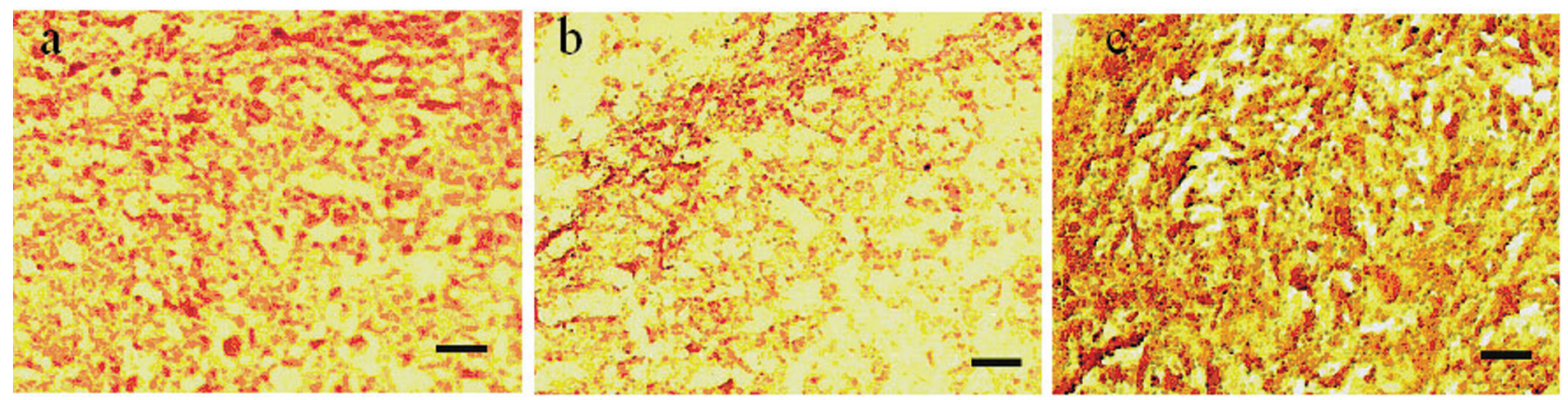

Figure 6. Immunohistochemical stainig of collagen type II in human bone marrov-derived MSCs (a), adipose tissue-derived MSCs (b) and chondrocytes (c). (Scalebar $=100 \mu \mathrm{m}$ for Figures 3, 4, 5, 6). 
et al. 2008). In our study, we compared in vitro chondrogenic potential of MSCs from bone marrow and adipose tissue. Biological material was obtained from two male donors who underwent planed surgeries. All sampling procedures were performed in agreement with the ethical principles.

Microscopical observation during in vitro cultivation showed that, bone marrow-derived MSCs and adipose tissue-derived MSCs displayed distinctive characteristics of stem cells (e.g. fibroblast-like morphology and intensive proliferation activity). Similar observations were published by other authors (Lin et al. 2005; Kern et al. 2006).

We found a similar phenotype of bone marrow-derived MSCs and adipose tissue- derived MSCs when examining cell surface markers. They were CD29, CD44, CD90 and CD105 positive, which are considered as general surface antigens of MSCs (Barry and Murphy 2004). On the other hand, they did not express CD31, CD34 and CD45, typical surface markers of haematopoietic stem cells (Pittenger et al. 1999; Baddoo et al. 2003). Moreover, they expressed HLA class I but not HLA class II. A similar phenomenon was observed in other types of undifferentiated cells, including MSCs (Le Blanc et al. 2003; Götherström et al. 2004).

Previous studies have reported the chondrogenic potential of human bone marrow-derived MSCs and adipose tissuederived MSCs (Guilak et al. 2004; Lee et al. 2004b; Pansky et al. 2007). We decided to compare if these potentials are identical. To induce chondrogenic differentiation we used three-dimensional culture system without supplementation of growth factors (e.g. TGF- $\beta 1$, TGF- $\beta 3$, BMP-6, IGF-1) which were used in other works (Pittenger et al. 1999; Schmitt et al. 2003; Indrawattana et al. 2004). This system is appropriate to start chondrogenesis in vitro because of high density of cells that provide not only cell-to-cell contact but also contact of cells and their microenvironment, which contains variety of signal molecules. Moreover, it mimics cellular condensation process and hypoxic environment occurring during chondrogenic differentiation in vivo (Denker et al. 1999; Stott et al. 1999).

Our results showed chondrogenic differentiation of both bone marrow-derived MSCs and adipose tissue-derived MSCs, which is in accordance with the findings of Bosnakovski et al. (2004), who reported the spontaneous chondrogenic differentiation of bovine MSCs in three-dimensional pellet culture. The chondrogenic nature of the differentiated MSCs in our aggregates was supported by the expression of a cartilaginous extracellular matrix, containing collagens and acid mucopolysaccharides as demonstrated by histological staining and immunohistochemical analysis. Comparison of the collagen type II production showed stronger staining in the samples of chondrocytes and bone marrow-derived MSCs when compared with those of adipose tissue-derived MSCs. This proved lowered chondrogenic potential of adipose tissue-derived MSCs. In contrast, Winter et al. (2003) demonstrated that bone marrow-derived MSCs and adipose tissue-derived MSCs are not significantly different in their ability to undergo chondrogenic differentiation. So the question of which MSCs are better replacements for chondrocytes in the cartilage tissue engineering is still under dispute (Lee et al. 2004b; Sakaguchi et al. 2005; Strem and Hedrick 2005).

In conclusion, we confirmed that both human bone marrow-derived MSCs and adipose tissue-derived MSCs underwent the process of chondrogenic differentiation. Comparative analysis shoved lowered chondrogenic potential of adipose tissue-derived MSCs in comparison with bone marrow-derived MSCs and chondrocytes. However, both evaluated MSCs may play important role in the cartilage tissue engineering.

Ackowledgement. This work was supported by grant of the Ministry of Health SR No. 2007/36-UK-07.

\section{References}

Baddoo M., Hill K., Wilkinson R., Gaupp D., Hughes C., Kopen G. C., Phinney D. G. (2003): Characterization of mesenchymal stem cells isolated from murine bone marrow by negative selection. J. Cell. Biochem. 89, 1235-1249

Banfi A., Bianchi G., Notaro R., Luzzatto L., Cancedda R., Quarto R. (2002): Replicative aging and gene expression in longterm cultures of human bone marrow stromal cells. Tissue Eng. 8, 901-910

Barry F. P., Murphy J. M. (2004): Mesenchymal stem cells: clinical applications and biological characterization. Int. J. Biochem. Cell Biol. 36, 568-584

Bosnakovski D., Mizuno M., Kim G., Ishiguro T., Okumura M., Iwanaga T., Kadosawa T., Fujinaga T. (2004): Chondrogenic differentiation of bovine bone marrow mesenchymal stem cells in pellet cultural system. Exp. Hematol. 32, 502-509

Bosnakovski D., Mizuno M., Kim G., Takagi S., Okumura M., Fujinaga T. (2005): Isolation and multilineage differentiation of bovine bone marrow mesenchymal stem cells. Cell Tissue Res. 319, 243-253

Brittberg M., Lindahl A., Nilsson A., Ohlsson C., Isaksson O., Peterson L. (1994): Treatment of deep cartilage defects in the knee with autologous chondrocyte transplantation. N. Engl. J. Med. 331, 889-895

Denker A. E., Haas A. R., Nicoll S. B., Tuan R. S. (1999): Chondrogenic differentiation of murine $\mathrm{C} 3 \mathrm{H} 10 \mathrm{~T} 1 / 2$ multipotential mesenchymal cells: I. Stimulation by bone morphogenetic protein-2 in high-density micromass cultures. Differentiation 64, 67-76

Gimble J., Guilak F. (2003): Adipose-derived adult stem cells: isolation, characterization, and differentiation potential. Cytotherapy 5, 362-369 
Götherström C., Ringdén O., Tammik C., Zetterberg E., Westgren M., Le Blanc K. (2004): Immunologic properties of human fetal mesenchymal stem cells. Am. J. Obstet. Gynecol. 190, 239-245

Guilak F., Awad H. A., Fermor B., Leddy H. A., Gimble J. M. (2004): Adipose-derived adult stem cells for cartilage tissue engineering. Biorheology 41, 389-399

Huang J. I., Zuk P. A., Jones N. F., Zhu M., Lorenz H. P., Hedrick M. H., Benhaim P. (2004): Chondrogenic potential of multipotential cells from human adipose tissue. Plast. Reconstr. Surg. 113, 585-594

Hunziker E. B., Rosenberg L. C. (1996): Repair of partial-thickness defects in articular cartilage: cell recruitment from the synovial membrane. J. Bone Joint Surg. Am. 78, 721-733

Indrawattana N., Chen G., Tadokoro M., Shann L. H., Ohgushi H., Tateishi T., Tanaka J., Bunyaratvej A. (2004): Growth factor combination for chondrogenic induction from human mesenchymal stem cell. Biochem. Biophys. Res. Commun. 320, 914-919

Jorgensen C., Djouad F., Bouffi C., Mrugala D., Noël D. (2008) Multipotent mesenchymal stromal cells in articular diseases. Best Pract. Res. Clin. Rheumatol. 22, 269-284

Kern S., Eichler H., Stoeve J., Klüter H., Bieback K. (2006): Comparative analysis of mesenchymal stem cells from bone marrow, umbilical cord blood, or adipose tissue. Stem Cells 24, 1294-1301

Le Blanc K., Tammik C., Rosendahl K., Zetterberg E., Ringdén O. (2003): HLA expression and immunologic properties of differentiated and undifferentiated mesenchymal stem cells. Exp. Hematol. 31, 890-896

Lee J. W., Kim Y. H., Kim S. H., Han S. H., Hahn S. B. (2004a): Chondrogenic differentiation of mesenchymal stem cells and its clinical applications. Yonsei Med. J. 45 (Suppl.), $41-47$

Lee R. H., Kim B., Choi I., Kim H., Choi H. S., Suh K., Bae Y. C., Jung J. S. (2004b): Characterization and expression analysis of mesenchymal stem cells from human bone marrow and adipose tissue. Cell. Physiol. Biochem. 14, 311-324

Lin Y., Luo E., Chen X., Liu L., Qiao J., Yan Z., Li Z., Tang W., Zheng X., Tian W. (2005): Molecular and cellular characterization during chondrogenic differentiation of adipose tissue-derived stromal cells in vitro and cartilage formation in vivo. J. Cell. Mol. Med. 9, 929-939

Pansky A., Roitzheim B., Tobiasch E. (2007): Differentiation potential of adult human mesenchymal stem cells. Clin. Lab. 53, 81-84

Pittenger M. F., Mackay A. M., Beck S. C., Jaiswal R. K., Douglas R., Mosca J. D., Moorman M. A., Simonetti D. W., Craig S., Marshak D. R. (1999): Multilineage potential of adult human mesenchymal stem cells. Science 284, 143-147
Sakaguchi Y., Sekiya I., Yagishita K., Muneta T. (2005): Comparison of human stem cells derived from various mesenchymal tissues: superiority of synovium as a cell source. Arthritis Rheum. 52, 2521-2529

Salgado A. J., Oliveira J. T., Pedro A. J., Reis R. L. (2006): Adult stem cells in bone and cartilage tissue engineering. Curr. Stem Cell Res. Ther. 1, 345-364

Schmitt B., Ringe J., Haupl T., Notter M., Manz R., Burmester G. R., Sittinger M., Kaps C. (2003): BMP2 initiates chondrogenic lineage development of adult human mesenchymal stem cells in high-density culture. Differentiation 71, $567-577$

Schnabel M., Marlovits S., Eckhoff G., Fichtel I., Gotzen L., Vécsei V., Schlegel J. (2002): Dedifferentiation-associated changes in morphology and gene expression in primary human articular chondrocytes in cell culture. Osteoarthr. Cartil. 10, 62-70

Sohn D. H., Lottman L. M., Lum L. Y., Kim S. G., Pedowitz R. A., Coutts R. D., Sah R. L. (2002): Effect of gravity on localization of chondrocytes implanted in cartilage defects. Clin. Orthop. Rel. Res. 394, 254-262

Stott N. S., Jiang T. X., Chuong C. M. (1999): Successive formative stages of precartilaginous mesenchymal condensations in vitro: modulation of cell adhesion by Wnt-7A and BMP-2. J. Cell. Physiol. 180, 314-324

Strehl R., Tallheden T., Sjogren-Jansson E., Minuth W. W., Lindahl A. (2005): Long-term maintenance of human articular cartilage in culture for biomaterial testing. Biomaterials 26, 4540-4549

Strem B. M., Hedrick M. H. (2005): The growing importance of fat in regenerative medicine. Trends Biotechnol. 23, 64-66

Tew S. R., Kwan A. P., Hann A., Thomson B. M., Archer C. W. (2000): The reactions of articular cartilage to experimental wounding: role of apoptosis. Arthritis Rheum. 43, 215-225

Tuli R., Li W. J., Tuan R. S. (2003): Current state of cartilage tissue engineering. Arthritis Res. Ther. 5, 235-238

Winter A., Breit S., Parsch D., Benz K., Steck E., Hauner H., Weber R. M., Ewerbeck V., Richter W. (2003): Cartilagelike gene expression in differentiated human stem cell spheroids: a comparison of bone marrow-derived and adipose tissue-derived stromal cells. Arthritis Rheum. 48, 418-429

Zuk P. A., Zhu M., Mizuno H., Huang J., Futrell J. W., Katz A. J., Benhaim P., Lorenz H. P., Hedrick M. H. (2001): Multilineage cells from human adipose tissue: implications for cell-based therapies. Tissue Eng. 7, 211-228

Received: August 28, 2008

Final version accepted: January 8, 2009 